\title{
Effect of mass transfer channels on flexural strength of C/SiC composites fabricated by femtosecond laser assisted CVI method with optimized laser power
}

\author{
Jing $\mathrm{WANG}^{\dagger}$, Liyang $\mathrm{CAO}^{\dagger}$, Yunhai ZHANG, \\ Yongsheng LIU*, Hui FANG, Jie CHEN \\ Science and Technology on Thermostructural Composites Materials Laboratory, \\ Northwestern Polytechnical University, Xi'an 710072, China
}

Received: August 16, 2020; Revised: September 23, 2020; Accepted: October 26, 2020

(c) The Author(s) 2020.

\begin{abstract}
In this study, femtosecond laser assisted-chemical vapor infiltration (LA-CVI) was employed to produce $\mathrm{C} / \mathrm{SiC}$ composites with 1,3 , and 5 rows of mass transfer channels. The effect of laser machining power on the quality of produced holes was investigated. The results showed that the increase in power yielded complete hole structures. The as-obtained $\mathrm{C} / \mathrm{SiC}$ composites with different mass transfer channels displayed higher densification degrees with flexural strengths reaching $546 \pm$ $15 \mathrm{MPa}$ for row mass transfer channel of 3 . The strengthening mechanism of the composites was linked to the increase in densification and formation of "dense band" during LA-CVI process. Multiphysics finite element simulations of the dense band and density gradient of LA-CVI C/SiC composites revealed $\mathrm{C} / \mathrm{SiC}$ composites with improved densification and lower porosity due to the formation of "dense band" during LA-CVI process. In sum, LA-CVI method is promising for future preparation of ceramic matrix composites with high densities.

Keywords: $\mathrm{C} / \mathrm{SiC}$; laser assisted-chemical vapor infiltration (LA-CVI); mass transfer channels; laser power; flexural strength
\end{abstract}

\section{Introduction}

Continuous fiber-reinforced ceramic matrix composites (CMC) are currently explored as new generation thermal structural materials for use in aero-engines with increased performances [1-4]. Such engines require thermal components with superior strength performance and high-precision machinings, such as combustors

$\dagger$ Jing Wang and Liyang Cao contributed equally to this work.

* Corresponding author.

E-mail: yongshengliu@nwpu.edn.cn and turbine blades with film cooling holes [5]. To this end, $\mathrm{C} / \mathrm{SiC}$ composites are promising materials with excellent thermal and mechanical properties, as well as superior ablation resistance [6].

$\mathrm{C} / \mathrm{SiC}$ composites are conventionally prepared by reaction melt infiltration (RMI) [7], precursor infiltration pyrolysis (PIP) [8-10], and chemical vapor infiltration (CVI) [3,11]. In particular, CVI is considered as an advanced manufacturing technology [2] but still suffers from the unavoidable "bottleneck effect" that blocks the depositing channels during the infiltration process and leads to limited densification. Hence, new-types of 
CVI have been explored, including heatless assisted CVI (HCVI) [12], microwave-assisted CVI (MCVI) $[13,14]$, and thermal gradient isobaric CVI (TG-CVI) $[15,16]$. HCVI could achieve faster and greater infiltration uniformity of $\mathrm{SiC}$ matrices with temperature gradient in the fiber preform, overcoming problems associated with slow diffusion and restricted permeability. MCVI is advantageous in terms of absorption of controlled microwave energy [13], so that fiber preform could be densified from the inside out. For instance, Bruneton et al. [17] used TG-CVI to move the dense zone from inside to the outside of fiber preform, leading to a rapid increase in density of the materials from 0.41 to $1.54 \mathrm{~g} / \mathrm{cm}^{3}$ within $26 \mathrm{~h}$. However, such CVI method failed to achieve stable equipment and techniques.

On the other hand, since $\mathrm{C} / \mathrm{SiC}$ composites are typical hard and brittle materials to machine, non-traditional machining technologies have recently been developed and tested. These include abrasive water jet machining [18], ultrasonic machining [19], and laser machining [20,21]. Among these, abrasive water jet machining and ultrasonic machining partly destroy the materials due to the formation of brittle fractures, leading to reduced material strength [22]. As a non-contact processing technology, laser processing has a wider range of applications than other processing technologies, especially for hard and brittle materials, such as ceramics and ceramic matrix composites. However, only a handful of research papers dealing with laser machining of ceramic matrix composites have so far been published, in which most focus on picosecond laser. For example, Zhang et al. [5] processed microholes in $\mathrm{C} / \mathrm{SiC}$ composites by high power picosecond laser and found the processing quality to be affected by different processing parameters, including helical line width and spacing, machining time, and scanning speed. In particular, minimum helical line spacing $(5 \mu \mathrm{m})$, smaller helical line width $(8 \mu \mathrm{m})$, and optimal machining time/speed would lead to good processing quality. Liu et al. [23] employed picosecond laser to process micro-holes on $\mathrm{C} / \mathrm{SiC}$ composites and determined the effects of energy density and feeding speed. Both energy density and feeding speed showed remarkable influence on the quality of micro-holes, especially on the exit side and cross-section of micro-holes. Compared to picosecond laser, femtosecond laser processing combines ultra-fast laser technology with ultra-high precision positioning and microtechnique. Thus, femtosecond laser processing is not only characterized by low machining damage but also high machining accuracy. Besides, femtosecond laser possesses ultrahigh peak power, thereby focusing the laser energy on target areas and effectively controlling the diffraction phenomenon [24,25]. However, femtosecond laser machining has rarely been used on ceramic matrix composites and machining parameters have not yet been well identified.

Furthermore, existing machining processes are always used after the complete preparation of materials, causing irreversible damage to the materials after machining. We have recently developed a novel femtosecond laser assisted-chemical vapor infiltration (LA-CVI) [26] method by successfully combining the CVI method with femtosecond laser machining. Compared to other machining technologies, LA-CVI method can be defined as a middle-stage machining technology with reduced irreversible damage, as well as enhanced densification and mechanical properties due to the formation of "dense band". We have successfully studied the effects of parameters of LA-CVI to determine the optimal values, such as the initial density [27] of $\mathrm{C} / \mathrm{SiC}$ composites and diameter [28] of mass transfer channels. However, further analysis of the relationship between femtosecond laser processing parameters and the quality of mass transfer channels is required to gain a better understanding of the method. It should be noted that LA-CVI method does have limitations that femtosecond laser processing equipment is expensive. In addition, because the LACVI method is used in the middle stage of preparation of $\mathrm{C} / \mathrm{SiC}$ (CVI-laser process-CVI), the preparation period of the materials could be longer than traditional $\mathrm{C} / \mathrm{SiC}$ composites (CVI-process). However, it is still an advanced preparation technology of ceramic matrix composites.

In this study, LA-CVI method was used to fabricate $\mathrm{C} / \mathrm{SiC}$ composites. The effects of femtosecond laser power on the quality of mass transfer channels were first investigated. $\mathrm{C} / \mathrm{SiC}$ composites with different arrangements of mass transfer channels were then fabricated, and the influences of mass transfer channel arrangements on densification and flexural strength of $\mathrm{C} / \mathrm{SiC}$ composites were explored. Multiphysics finite element software was also employed to clarify the formation of "dense band" and uniform density distribution. 


\section{Experimental}

\section{1 Materials and preparation of $\mathrm{C} / \mathrm{SiC}$ composites with mass transfer channels}

The carbon fiber preform of the $\mathrm{C} / \mathrm{SiC}$ composites was fabricated by laminating plain two-dimensional (2D) weave carbon fiber clothes (T300, Toray, Japan). A four-axis laser micro-machining platform was employed to process the $\mathrm{C} / \mathrm{SiC}$ composites. The diameter of the mass transfer channel and thickness of the sample were set to 0.5 and $3 \mathrm{~mm}$, respectively. Helical scanning modes at $\mathrm{C} / \mathrm{SiC}$ composite processing powers of 10 , 100, 1000, 4000, and $8000 \mathrm{~mW}$ were selected. The arrangements and microstructures of mass transfer channels are provided in Fig. 1. The mass transfer channels in three-point flexural test samples LS1, LS3, and LS5 were set to 14,40 , and 68, respectively. For proper comparison, $\mathrm{C} / \mathrm{SiC}$ composites with no channels (LS0) were also prepared using the same CVI process.

\section{2 Characterization}

The density and open porosity of $\mathrm{C} / \mathrm{SiC}$ composites were measured by the Archimedes' method. The microstructures were observed by scanning electron microscopy (SEM, FEI, Helios G4 CX, USA) and surface chemical compositions were analyzed by energy dispersive spectrometry (EDS, EDAX, USA). The three-dimensional (3D) images of pore structures were portrayed by 3D surface profiling (NANOVEA, USA). The flexural strengths were measured by an electromechanical universal testing system (Instron 5567, UK) with a dimension of $60 \mathrm{~mm} \times 9 \mathrm{~mm} \times 3 \mathrm{~mm}$. The flexural strength measurements were obtained at the loading rate of $0.5 \mathrm{~mm} / \mathrm{min}$ following the ASTM C1341-00 guidelines. The mathematical model of LACVI was developed using MATLAB in combination with COMSOL multiphysics finite element analysis

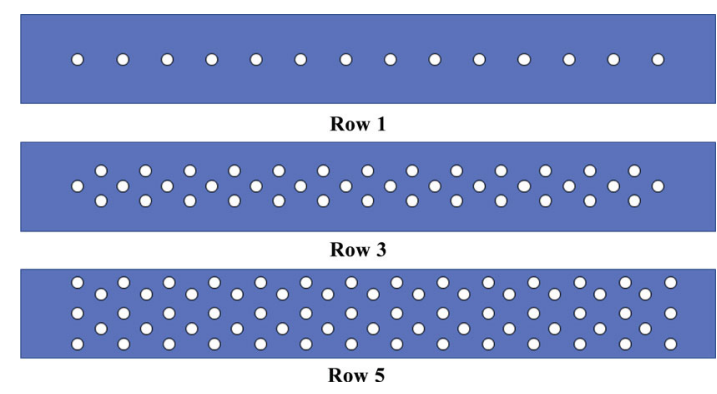

Fig. 1 Arrangements and microstructures of the mass transfer channels. software. Computed tomography (CT) measurement was used by microfocus CT detection system (diondo d2, Germany).

\section{Results and discussion}

\section{1 Effect of femtosecond laser power on quality of mass transfer channels}

The SEM images of femtosecond laser processing micro-holes of $\mathrm{C} / \mathrm{SiC}$ composite samples at the processing powers of 10,100,1000, 4000, and $8000 \mathrm{~mW}$ are depicted in Fig. 2. At $10 \mathrm{~mW}$, helical gap structures were clearly seen on the material surface. At powers of 100 and $1000 \mathrm{~mW}$, tapered blind holes were initially formed with large numbers of cauliflower-like processing chips deposited in channel interior, mainly adhering to the wall and bottom of the channel. At $4000 \mathrm{~mW}$, holes with higher quality but slight taper shapes were formed with some residual debris observed at the edge. Compared to $4000 \mathrm{~mW}$, more debris and minor damages in the materials at the edges were noticed at $8000 \mathrm{~mW}$. EDS analysis (Table 1) revealed the presence of $\mathrm{C}, \mathrm{O}$, and $\mathrm{Si}$ components of laser-processed materials. $\mathrm{O}$ content increased sharply with laser power. At processing power of $8000 \mathrm{~mW}$, the oxygen-silicon atomic ratio reached approximately 2 , indicating the formation of $\mathrm{SiO}_{2}$. The processing reactions can be summarized as follows:

$$
\begin{gathered}
\mathrm{C}+x \mathrm{O}_{2} \rightarrow 2 \mathrm{CO}_{x} \\
\mathrm{C}\left(\mathrm{sp}_{2}\right) \rightarrow \mathrm{C}\left(\mathrm{sp}_{3}\right) \\
2 \mathrm{SiC}+(x+y) \mathrm{O}_{2} \rightarrow 2 \mathrm{CO}_{x}+2 \mathrm{SiO}_{y}
\end{gathered}
$$

To gain a better understanding of the influence of power on the internal shape of the channel, 3D micromorphological sections were obtained. As shown in Fig. 3, the machining channel at the power of $100 \mathrm{~mW}$ looked like shallow blind hole. At $1000 \mathrm{~mW}$, the taper was smaller and the depth was profound. At $8000 \mathrm{~mW}$, the channels showed no obvious taper as depth increased. As depicted in Figs. 3 and 4, lower processing power led to moderate laser energy density, resulting in lower recoil pressure in the channels. The debris formed in the channel could not be ejected in time, hereby absorbing and reflecting subsequent laser energy and forming evident taper shaped channels. The distinct energy gradient in the hole is provided in Fig. 4(a). At processing power of $1000 \mathrm{~mW}$, large 

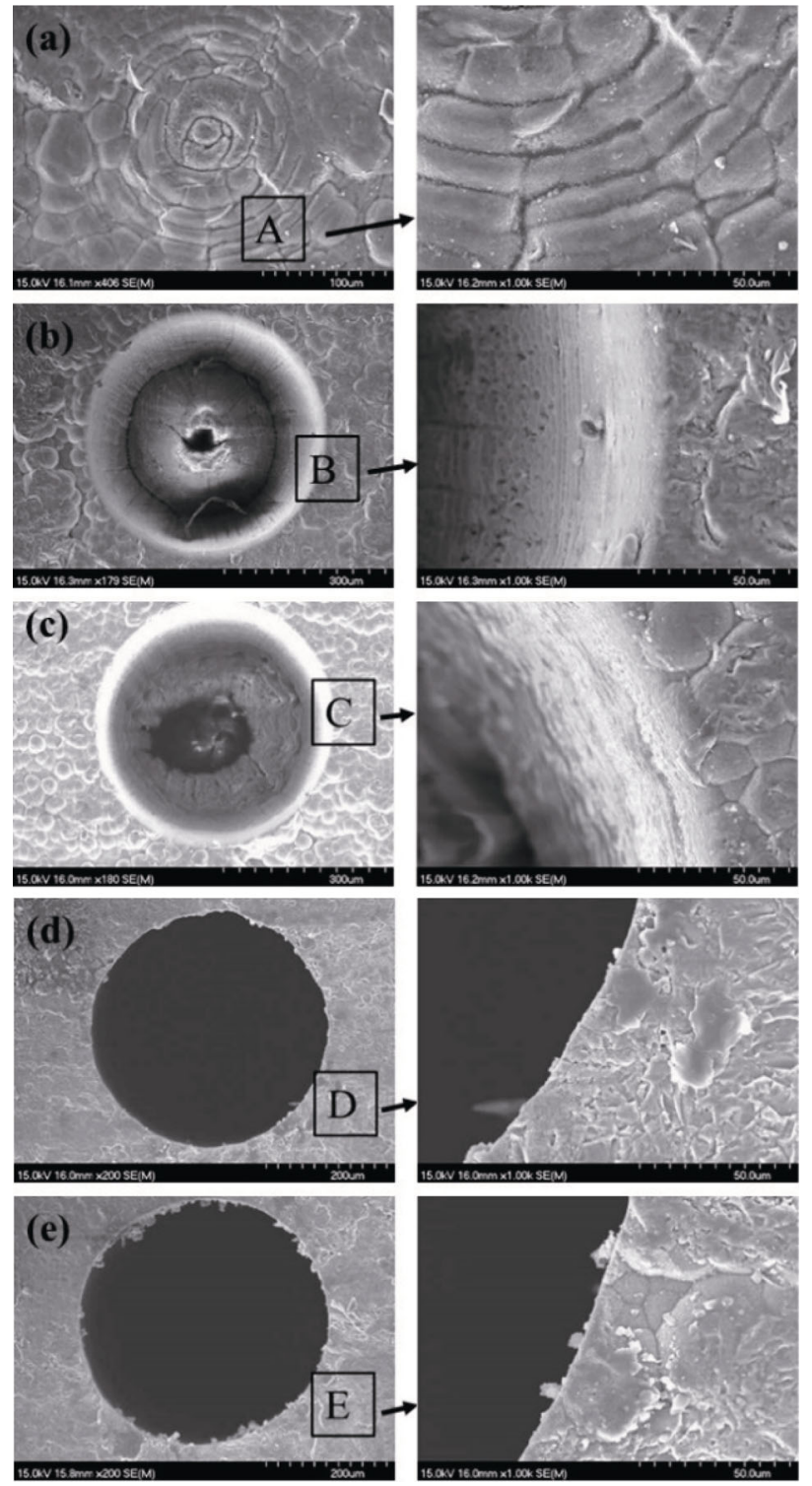

Fig. 2 Morphologies of $\mathrm{C} / \mathrm{SiC}$ femtosecond laser at different processing powers: (a) 10, (b) 100, (c) 1000, (d) 4000, and (e) $8000 \mathrm{~mW}$.

Table 1 EDS analyses of $\mathrm{C} / \mathrm{SiC}$ composites treated by different femtosecond laser helical line machinings

\begin{tabular}{cccc}
\hline \multirow{2}{*}{ Power $(\mathrm{mW})$} & \multicolumn{3}{c}{ Element content $(\%)$} \\
\cline { 2 - 4 } & $\mathrm{C}$ & $\mathrm{Si}$ & $\mathrm{O}$ \\
\hline 10 & 81.97 & 17.05 & 0.98 \\
100 & 75.02 & 19.95 & 5.03 \\
1000 & 61.10 & 22.50 & 16.40 \\
4000 & 55.85 & 25.69 & 18.46 \\
8000 & 35.79 & 40.90 & 23.31 \\
\hline
\end{tabular}

amounts of gaseous substances were formed during the drilling process. This, in turn, could generate high recoil pressure, resulting in the rapid ejection of the debris from the holes and reduced influence of the debris on subsequent laser action (Fig. 4(b)). At $8000 \mathrm{~mW}$, lower energy gradients and regular hole structures were noticed. However, superior power values led to serious damage and even ablative erosion of the material surface during femtosecond laser processing. According to the Nikiforovsky-Shemyakin principle [29] (Eq. (4)), the recoil pressure formed inside the channels led to local oppression on their entrances. The material was destroyed when the pressure at the entrance edge exceeded the destructive threshold.

$$
\int_{0}^{t} \sigma(t) \mathrm{d} t \geqslant J_{\mathrm{c}}
$$

where $\sigma(t)$ is the pressure at the entrance of the channel (related to the time accumulation $t$ ) and $J_{\mathrm{c}}$ represents the destructive threshold of the material.

\section{2 Densification of $\mathrm{C} / \mathrm{SiC}$ composites with mass transfer channels}

Table 2 shows the parameters used in our previous studies $[26-28,30]$. Based on the above research analyses, $8000 \mathrm{~mW}$ laser power was employed as an optimal value to produce different arrangements of mass transfer channels. In Table 3, the density and porosity of $\mathrm{C} / \mathrm{SiC}$ composites remarkably improved as the longitudinal row of mass transfer channels increased. The density of LS5 was estimated to $2.28 \mathrm{~g} / \mathrm{cm}^{3}$, equivalent to $17 \%$ improvement when compared to traditional CVI C/SiC composites. Besides, the porosity of LS5 reduced $0.89 \%$.

The microstructures of LA-CVI C/SiC composites with different arrangements of mass transfer channels are displayed in Fig. 5, and the mechanism of density improvement is provided in Fig. 6. Some closed pores were randomly distributed in $\mathrm{C} / \mathrm{SiC}$ composites, especially in contact areas between the fiber and matrix. During the laser processing, $\mathrm{SiC}$ matrix and carbon fiber gasified due to the extremely high transient temperature, thereby reopening the closed pores at the ablation surface (Fig. 6) and later infiltrating the $\mathrm{SiC}$ matrix during CVI process to yield composites with enhanced compactness. Besides, "dense band" structures formed during LA-CVI process benefited the densification and flexural strength of $\mathrm{C} / \mathrm{SiC}$ composites.

To theoretically assess the effects of gas mass transfer on the densification process and verify the enhanced densification mechanism, MATLAB was combined with COMSOL multiphysics finite element analysis software 

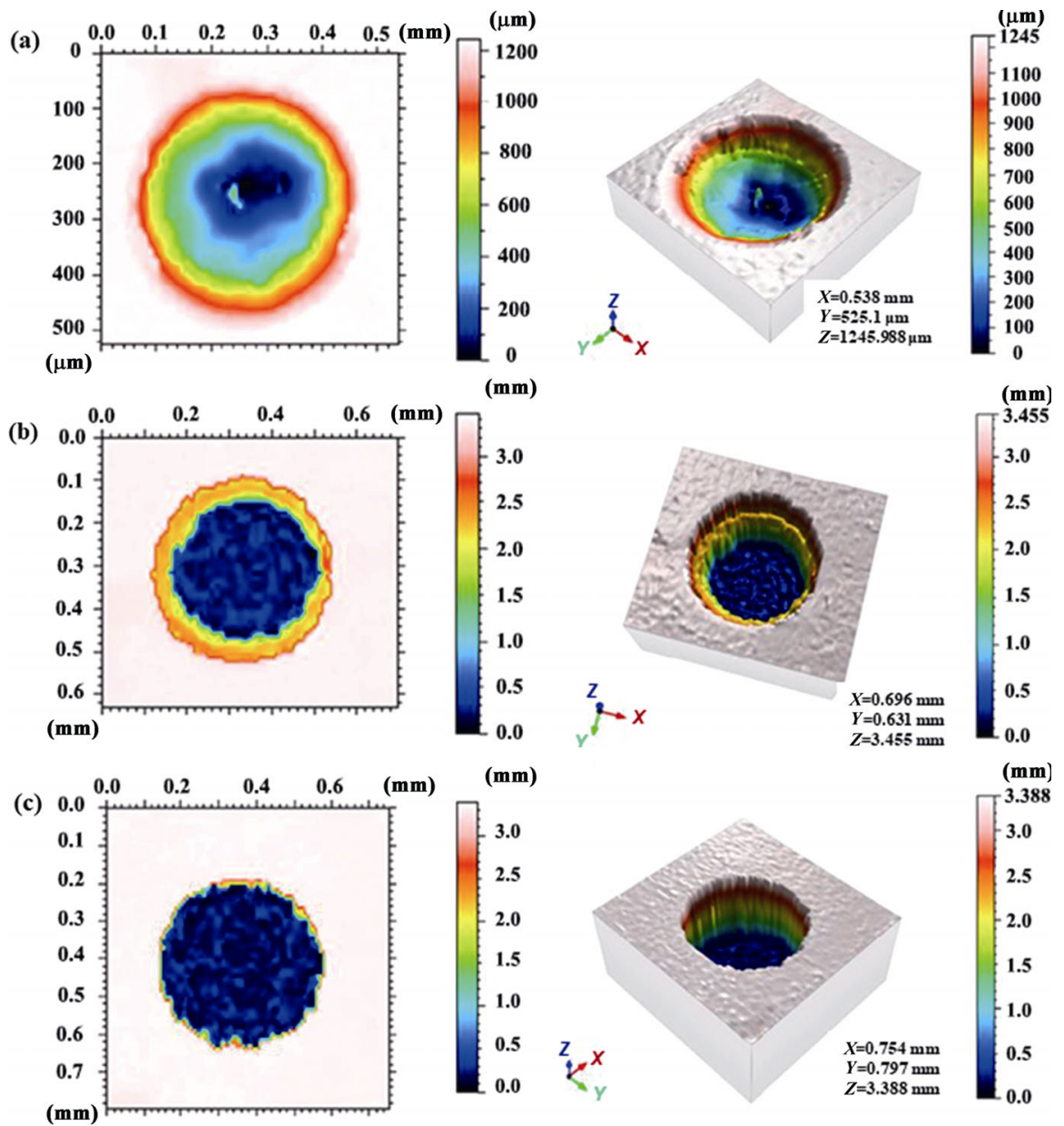

Fig. 3 3D images of hole structures obtained at (a) 100, (b) 1000, and (c) $8000 \mathrm{~mW}$ femtosecond laser power.
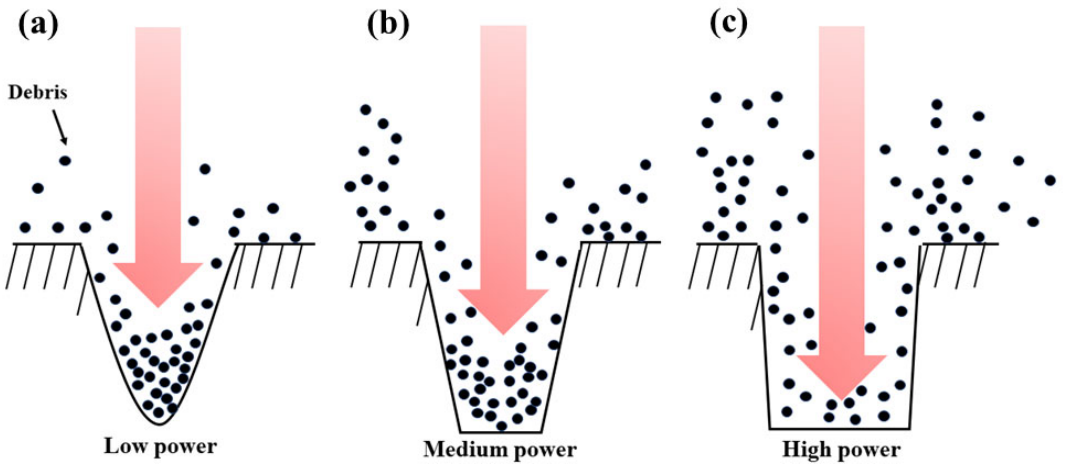

Fig. 4 Processing models of $\mathrm{C} / \mathrm{SiC}$ composites by different femtosecond laser power.

Table 2 Processing parameters used in recent studies

\begin{tabular}{ccccc}
\hline $\begin{array}{c}\text { Process } \\
\text { parameter }\end{array}$ & $\begin{array}{c}\text { Laser } \\
\text { power }\end{array}$ & $\begin{array}{c}\text { Scanning } \\
\text { mode }\end{array}$ & $\begin{array}{c}\text { Scanning } \\
\text { interval } \\
(\mu \mathrm{m})\end{array}$ & $\begin{array}{c}\text { Scanning } \\
\text { speed } \\
(\mathrm{mm} / \mathrm{s})\end{array}$ \\
\hline$[26-28,30]$ & $5 \mathrm{~mW}$ & $\begin{array}{c}\text { Helical } \\
\text { scanning }\end{array}$ & 3 & 450 \\
This study & $\begin{array}{c}\text { Series of } \\
\text { laser power }\end{array}$ & $\begin{array}{c}\text { Helical } \\
\text { scanning }\end{array}$ & 6 & 600 \\
\hline
\end{tabular}

Table 3 Properties of $\mathrm{C} / \mathrm{SiC}$ composites prepared with a different arrangement for channels

\begin{tabular}{ccccc}
\hline Sample & $\begin{array}{c}\text { Row } \\
\text { number }\end{array}$ & $\begin{array}{c}\text { Density } \\
\left(\mathrm{g} / \mathrm{cm}^{3}\right)\end{array}$ & $\begin{array}{c}\text { Porosity } \\
(\%)\end{array}$ & $\begin{array}{c}\text { Fiber content } \\
(\%)\end{array}$ \\
\hline LS0 & 0 & 1.95 & $13.48 \pm 0.85$ & 42.5 \\
LS1 & 1 & 2.12 & $11.22 \pm 0.76$ & 42.5 \\
LS3 & 3 & 2.23 & $11.05 \pm 0.66$ & 42.5 \\
LS5 & 5 & 2.28 & $10.89 \pm 0.94$ & 42.5 \\
\hline
\end{tabular}




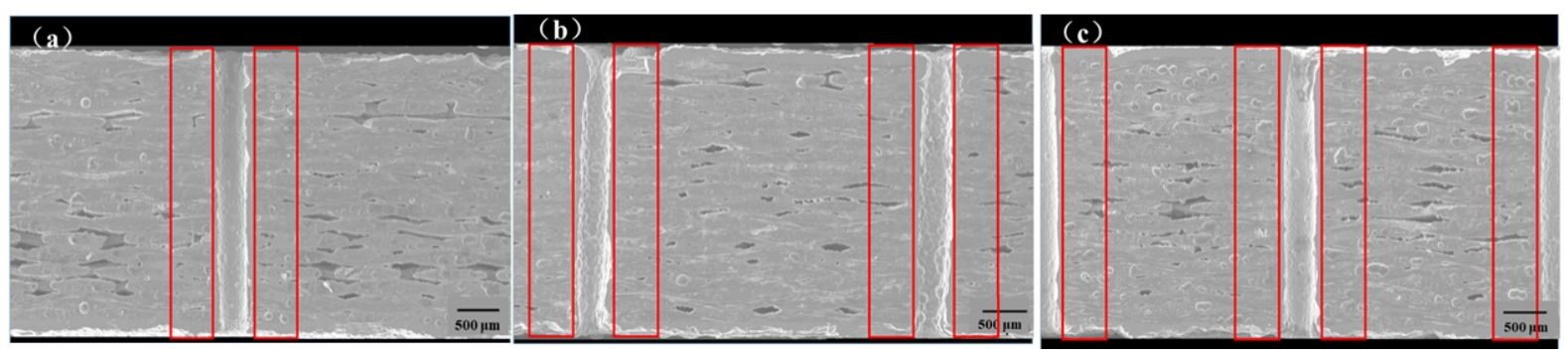

Fig. 5 Microstructures of LA-CVI C/SiC composites with different arrangements of channels: (a) 1, (b) 3, and (c) 5 rows.

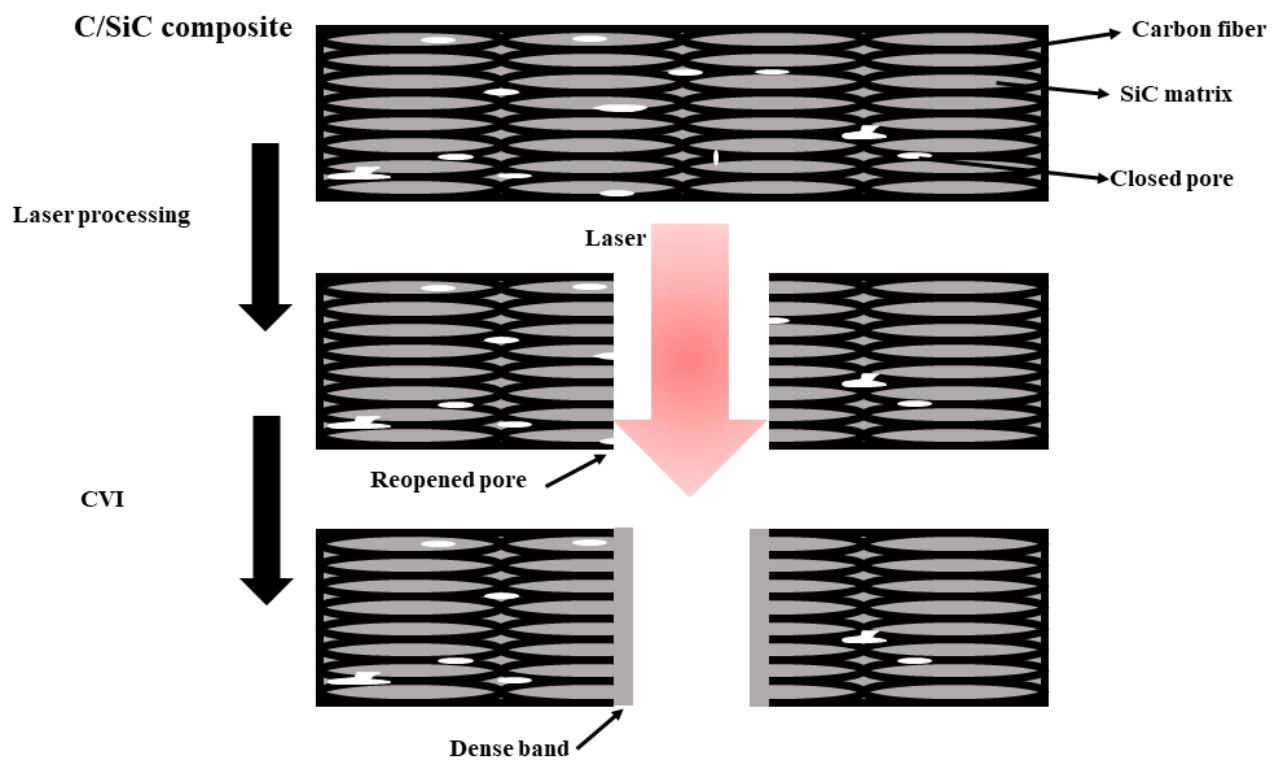

Fig. 6 Microstructure diagram of LA-CVI C/SiC composite.

to simulate the density distributions of composites with different arranged mass transfer channels. The simulations were performed under the following assumptions and conditions: (i) Gas mass was conserved in Eq. (5); (ii) the reaction was based on the steady-state regimen; (iii) constant temperature was maintained during CVI process; and (iv) all gases in the reaction were considered as ideal. The simulation results agreed well with the density and microstructure. First, the formation of "dense band" was clearly observed in each mass transfer channel (red circles in Figs. 7(b)-7(d)). Second, the density gradient in Fig. 7(a) was larger than that in Figs. 7(b)-(d). Furthermore, large numbers of rows yielded more uniform density distributions since more "dense band" surrounded by dense areas were introduced into $\mathrm{C} / \mathrm{SiC}$ composites, leading to more microchannels in MTS $\left(\mathrm{CH}_{3} \mathrm{SiCl}_{3}\right.$ gas in CVI) flow. This, in turn, resulted in better deposition rates and more accumulated $\mathrm{SiC}$ matrices.

$$
\mathrm{CH}_{3} \mathrm{SiCl}_{3}(\mathrm{v}) \stackrel{\text { Excess } \mathrm{H}_{2}}{\longrightarrow} \mathrm{SiC}(\mathrm{s})+3 \mathrm{HCl}(\mathrm{v})
$$
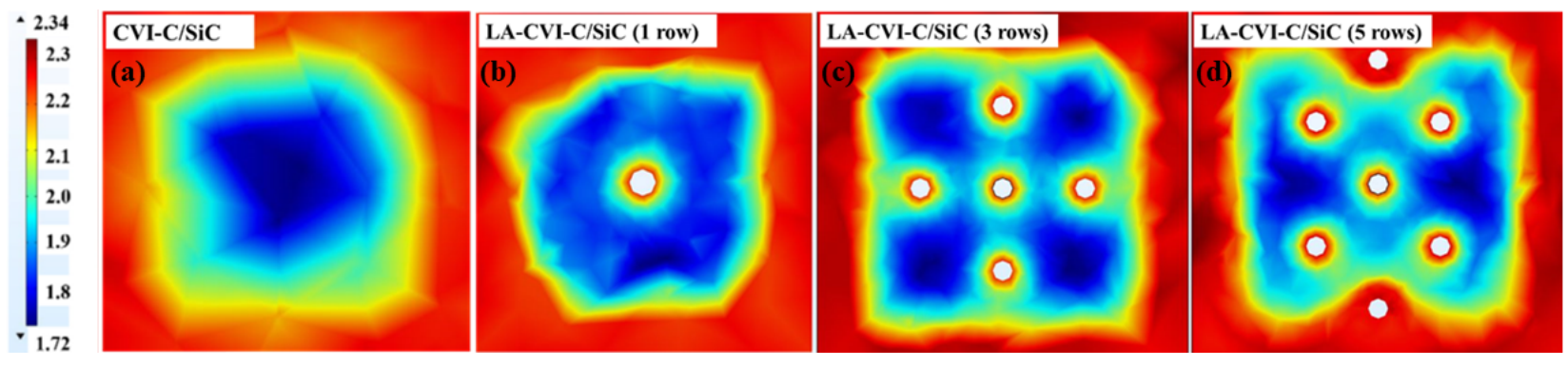

Fig. 7 Density distributions of LA-CVI-C/SiC with different arrangements of channels. 


\section{3 Flexural strengths of $\mathrm{C} / \mathrm{SiC}$ composites with mass transfer channels}

The flexural strengths of $\mathrm{C} / \mathrm{SiC}$ composites with different arrangements of mass transfer channels are presented in Table 4 and Fig. 8. Similar to the effects of the diameter [28], the arrangement of channels also showed noticeable influences on the flexural strengths. Compared to traditional composites (flexural strength $470 \pm 10 \mathrm{MPa}), \mathrm{C} / \mathrm{SiC}$ composites with mass transfer channels of 1 and 3 rows displayed improved flexural strengths $(528 \pm 12$ and $546 \pm 15 \mathrm{MPa}$, respectively). Note that the largest increase reached $16.2 \%$. As explained in Section 3.2, the densification of $\mathrm{C} / \mathrm{SiC}$ composites improved as row channel rose since reopened pores infiltrated the structures to form more "dense band". Higher density meant more SiC matrix content, representing higher cohesive energy of SiC. Furthermore, the pinning effect generated by the "dense band" could strengthen the interlaminar adhesion.

The microstructures of $\mathrm{C} / \mathrm{SiC}$ composites with different arrangements of mass transfer channels are given in Figs. 9 and 10. The fracture toughness of each composite might be revealed by crack propagation. The

Table 4 Flexural strength of $\mathrm{C} / \mathrm{SiC}$ composites with different arrangements of mass transfer channels

\begin{tabular}{ccc}
\hline Sample & Row number & Flexural strength (MPa) \\
\hline LS0 & 0 & $470 \pm 10$ \\
LS1 & 1 & $528 \pm 12$ \\
LS3 & 3 & $546 \pm 15$ \\
LS5 & 5 & $461 \pm 13$ \\
\hline
\end{tabular}
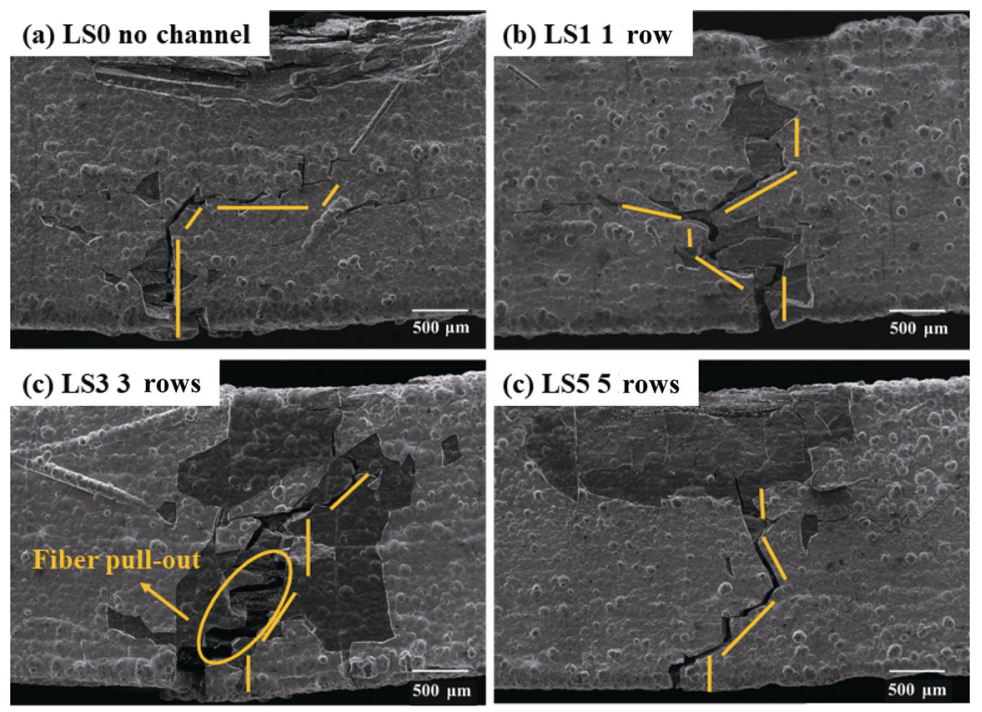

Fig. 9 SEM images of crack propagation of $\mathrm{C} / \mathrm{SiC}$ with different arrangements of mass transfer channels. 

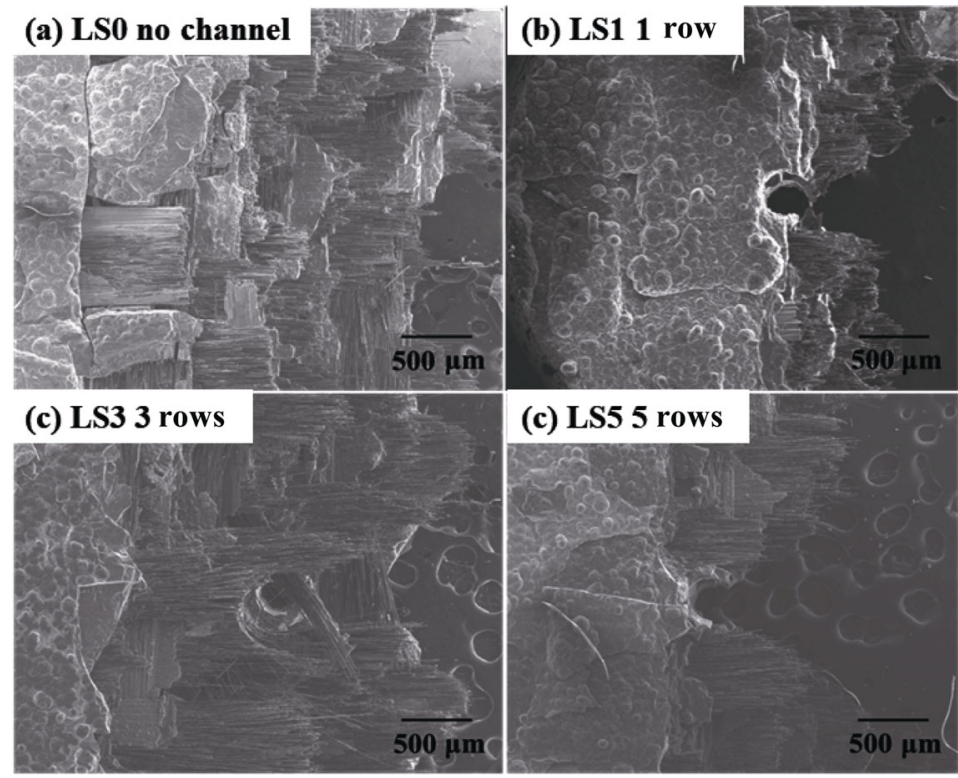

(c) LS5 5 rows

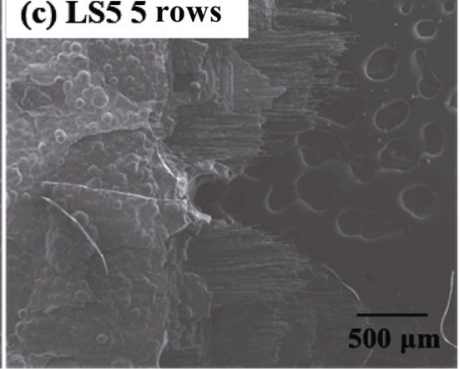

Fig. 10 SEM images of fracture surfaces of $\mathrm{C} / \mathrm{SiC}$ with different arrangements of mass transfer channels.

mode. $\mathrm{C} / \mathrm{SiC}$ composites with mass transfer channels possessed more complex phase composition owing to the presence of "dense band" and crystalline structure transition of $\mathrm{SiC}$ and $\mathrm{C}$ phase caused by laser ablation [32].

In Fig. 10(a), composites with no channels showed shorter lengths of fiber pull-out and fracture morphologies. However, $\mathrm{C} / \mathrm{SiC}$ composites with 3 rows of channel presented fibers and fiber bundle pull-out (Fig. 10(c)). Compared to Fig. 10(a), longer and more fibers with irregular length and bundle pull-out were observed in Figs. 10(b)-10(d). Also, more prominent layer-by-layer failure mode and rough fracture morphologies were noticed in Fig. 10(c). Hence, $\mathrm{C} / \mathrm{SiC}$ composites with row channel of 3 presented proper channel arrangement. However, excess of holes per unit volume was seen in $\mathrm{C} / \mathrm{SiC}$ composites with row channel of 5 , negatively impacting the defects instead of reinforcing them. However, when the quantities of holes (mass transfer channels) were excessive, the defect effect brought by holes was greater than its enhancement effect. On the other hand, during the fracture process, there were a lot of microcracks in the $\mathrm{C} / \mathrm{SiC}$ composites, especially around the holes which could be proved by CT image (Fig. 11(a)). The microcrack propagation path was depicted in Fig. 11, when the quantities of channels were at high level (Fig. 11(c)), the microcrack around one channel would propagate and contact with another microcrack around another channel, and the new and bigger microcrack
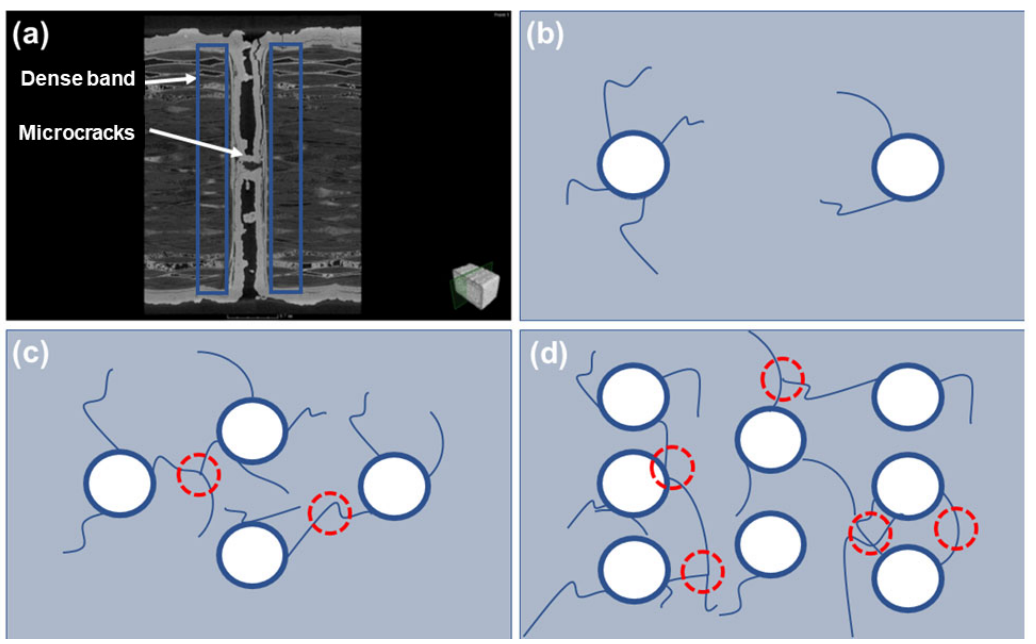

Fig. 11 Schematic diagrams of microcrack propagation with different hole structures. 
would propagate from contact site which was labeled in red circle in Fig. 11. When the quantities of channels were at higher levels (Fig. 11(d)), abundant of microcracks connected and propagated along with longer path until the surface of the material. As a result, large quantities of channels accelerated crack propagation, which led to degradation of flexural strength.

\section{Conclusions}

$\mathrm{C} / \mathrm{SiC}$ composites with different mass transfer channels were successfully prepared by a novel CVI technique. The coordinate relationship between "laser power-hole quality-material strength" was established. The specific conclusions are as follows:

The laser machining power of LA-CVI significantly affected the hole quality. At low power, debris could not be ejected from the holes, yielding taper blind holes. As the power increased, the quality of holes improved due to the recoil pressure formed in the holes, allowing the ejection of excess debris. Besides, the as-obtained $\mathrm{C} / \mathrm{SiC}$ composites exhibited excellent flexural strengths.

The influence of the arrangement of mass transfer channels on composite densification and flexural strength revealed $\mathrm{C} / \mathrm{SiC}$ composites with improved densification and lower porosity due to the formation of "dense band" during LA-CVI process, as shown by multiphysics finite element analysis. The flexural strength of LA-CVI C/SiC composite rose to $546 \pm 15 \mathrm{MPa}$ for row mass transfer channel of 3 , equivalent to $16.2 \%$ increase. The strengthening mechanism was attributed to crack deflection and sufficient energy consumption caused by the fiber pull-out and layered damage of the composites.

In sum, the proposed complete LA-CVI method looks promising for future preparation of ceramic matrix composites with high densification and outstanding mechanical properties.

\section{Acknowledgements}

The authors acknowledge the support from the National Natural Science Foundation of China (Nos. 51972269 and 51672217), the Fundamental Research Funds for the Central Universities (No. 3102019ghxm014), and the Creative Research Foundation of the Science and Technology on Thermostructural Composite Materials Laboratory (No. JCKYS2020607001).

\section{References}

[1] Krenkel W. Carbon fiber reinforced CMC for highperformance structures. Int J Appl Ceram Technol 2005, 1: 188-200.

[2] Chen LQ, Yin XW, Fan XM, et al. Mechanical and electromagnetic shielding properties of carbon fiber reinforced silicon carbide matrix composites. Carbon 2015, 95: 10-19.

[3] Xu YD, Cheng LF, Zhang LT, et al. Mechanical properties of 3D fiber reinforced C/SiC composites. Mater Sci Eng: A 2001, 300: 196-202.

[4] Krenkel W, Berndt F. C/C-SiC composites for space applications and advanced friction systems. Mater Sci Eng: A 2005, 412: 177-181.

[5] Zhang RH, Li WN, Liu YS, et al. Machining parameter optimization of $\mathrm{C} / \mathrm{SiC}$ composites using high power picosecond laser. Appl Surf Sci 2015, 330: 321-331.

[6] Lamouroux F, Bertrand S, Pailler R, et al. Oxidationresistant carbon-fiber-reinforced ceramic-matrix composites. Compos Sci Technol 1999,

[7] Li JX, Liu YS, Nan BY, et al. Microstructure and properties of C/SiC-diamond composites prepared by the combination of CVI and RMI. Adv Eng Mater 2019, 21: 1800765.

[8] Zhu YZ, Huang ZR, Dong SM, et al. Manufacturing 2D carbon-fiber-reinforced $\mathrm{SiC}$ matrix composites by slurry infiltration and PIP process. Ceram Int 2008, 34: 12011205.

[9] Xiang Y, Li W, Wang S, et al. Oxidation behavior of oxidation protective coatings for PIP-C/SiC composites at $1500{ }^{\circ} \mathrm{C}$. Ceram Int 2012, 38: 9-13.

[10] Jin W, Si Z, Lu Y, et al. Oxidation behavior and hightemperature flexural property of CVD-SiC-coated PIP-C/ SiC composites. Ceram Int 2018, 44: 16583-16588.

[11] Xu YD, Cheng LF, Zhang LT. Carbon/silicon carbide composites prepared by chemical vapor infiltration combined with silicon melt infiltration. Carbon 1999, 37: 1179-1187.

[12] Tang SF, Deng JY, Du HF, et al. Fabrication and microstructure of $\mathrm{C} / \mathrm{SiC}$ composites using a novel heaterless chemical vapor infiltration technique. $J \mathrm{Am}$ Ceram Soc 2005, 88: 3253-3255.

[13] Zou JZ, Zeng XR, Xiong XB. Microwave assisted chemical vapor infiltration to prepare carbon/carbon composites. Carbon 2009, 47: 2941-2942.

[14] Gupta D, Evans JW. A mathematical model for chemical vapor infiltration with microwave heating and external cooling. J Mater Res 1991, 6: 810-818.

[15] Vignoles GL, Duclous R, Gaillard S. Analytical stability study of the densification front in carbon- or ceramicmatrix composites processing by TG-CVI. Chem Eng Sci 2007, 62: 6081-6089.

[16] Golecki I. Rapid vapor-phase densification of refractory composites. Mater Sci Eng: R: Rep 1997, 20: 37-124. 
[17] Bruneton E, Narcy B, Oberlin A. Carbon-carbon composites prepared by a rapid densification process I: Synthesis and physico-chemical data. Carbon 1997, 35: 1593-1598.

[18] Zhang FL. Machining mechanism of abrasive water jet on ceramics. Key Eng Mat 2010, 426-427: 212-215.

[19] Zou KR, Wang C, Zhang LY. Experimental study of ultrasonic vibration drilling ceramic material. Appl Mech Mater 2012, 217-219: 1863-1868.

[20] Fiedler S, Irsig R, Tiggesbäumker J, et al. Machining of biocompatible ceramics with femtosecond laser pulses. Biomed Tech 2013, 58(S1): 000010151520134093.

[21] Burck P, Wiegel K. Laser machining of $\mathrm{Si}_{3} \mathrm{~N}_{4}$ ceramics. Opt Quantum Electron 1995, 27: 1349-1358.

[22] Pachaury Y, Tandon P. An overview of electric discharge machining of ceramics and ceramic based composites. $J$ Manuf Process 2017, 25: 369-390.

[23] Liu YS, Wang CH, Li WN, et al. Effect of energy density and feeding speed on micro-hole drilling in $\mathrm{C} / \mathrm{SiC}$ composites by picosecond laser. J Mater Process Technol 2014, 214: 3131-3140.

[24] Chichkov BN, Momma C, Nolte S, et al. Femtosecond, picosecond and nanosecond laser ablation of solids. Appl Phys A 1996, 63: 109-115.

[25] Liu X, Du D, Mourou G. Laser ablation and micromachining with ultrashort laser pulses. IEEE J Quantum Electron 1997, 33: 1706-1716.

[26] Wang J, Cheng LF, Liu YS, et al. Enhanced densification and mechanical properties of carbon fiber reinforced silicon carbide matrix composites via laser machining aided chemical vapor infiltration. Ceram Int 2017, 43: 11538-11541.

[27] Wang J, Zhang YH, Liu YS, et al. Effects of initial density during laser machining assisted CVI process and its influence on strength of C/SiC composites. Ceram Int 2020,
46: $11743-11746$.

[28] Wang J, Chen X, Guan K, et al. Effects of channel modification on microstructure and mechanical properties of $\mathrm{C} / \mathrm{SiC}$ composites prepared by LA-CVI process. Ceram Int 2018, 44: 16414-16420.

[29] Shemyakin EI, Kurlenya MV, Oparin VN, et al. Zonal disintegration of rocks around underground workings. IV. Practical applications. Sov Min Sci 1989, 25: 297-302.

[30] Wang J, Cao LY, Liu YS, et al. Fabrication of improved flexural strength $\mathrm{C} / \mathrm{SiC}$ composites via LA-CVI method using optimized spacing of mass transfer channels. J Eur Ceram Soc 2020, 40: 2828-2833.

[31] Cao LY, Liu YS, Zhang YH, et al. Enhancing thermal conductivity of $\mathrm{C} / \mathrm{SiC}$ composites containing heat transfer channels. J Eur Ceram Soc 2020, 40: 3520-3527.

[32] Wu ML, Ren CZ, Xu HZ. Comparative study of micro topography on laser ablated $\mathrm{C} / \mathrm{SiC}$ surfaces with typical uni-directional fibre ending orientations. Ceram Int 2016, 42: 7929-7942.

Open Access This article is licensed under a Creative Commons Attribution 4.0 International License, which permits use, sharing, adaptation, distribution and reproduction in any medium or format, as long as you give appropriate credit to the original author(s) and the source, provide a link to the Creative Commons licence, and indicate if changes were made.

The images or other third party material in this article are included in the article's Creative Commons licence, unless indicated otherwise in a credit line to the material. If material is not included in the article's Creative Commons licence and your intended use is not permitted by statutory regulation or exceeds the permitted use, you will need to obtain permission directly from the copyright holder.

To view a copy of this licence, visit http://creativecommons. org/licenses/by/4.0/. 